\title{
Compartilhamentos e singularizações: A constituição social da subjetividade
}

\author{
Shares and singularizations: Social constitution of subjectivity
}

Gilberto Lima dos Santos ${ }^{[a]}$, Antonio Marcos Chaves ${ }^{[b]}$

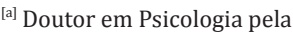
Universidade Federal da Bahia (UFBA), professor adjunto da Universidade do Estado da Bahia (Uneb), Câmpus VII, Senhor do Bonfim, BA - Brasil, e-mail: glsantos@uneb.br

${ }^{[b]}$ Doutor em Psicologia Escolar e do Desenvolvimento Humano pela Universidade de São Paulo (USP), professor associado da Universidade Federal da Bahia (UFBA), Salvador, BA - Brasil, e-mail: amchaves@ufba.br
\end{abstract}

Recebido: 05/10/2011 Received: $10 / 05 / 2011$

Aprovado: 09/05/2012 Approved: 05/09/2012

\begin{abstract}
Resumo
Neste estudo, propõe-se o conceito de singularização como mais uma possibilidade de aproximação à compreensão de como a subjetividade é constituída socialmente, de acordo com a abordagem da psicologia histórico-cultural. Inicia-se com uma retrospectiva histórica da introdução do sentido e do significado na psicologia, ao longo da Modernidade, marcada por resistências à consideração da cultura na constituição dos fenômenos psicológicos. A partir daí, discutem-se os aportes teóricos trazidos pelos conceitos de internalização, apropriação e conversão. Essa discussão aponta a falta de uma explicação para a transformação do conhecimento coletivo em conhecimento individual sem viés dualista. Conclui-se, por fim, que o conceito de singularização ressalta o caráter ativo do sujeito e sua ação interpretativa, ao criar versões singulares para os significados, ao mesmo tempo em que os reproduz nos intercâmbios sociais. Esclarece-se, ainda, que essas versões são baseadas nos sentidos, os quais, por sua vez, são articulados com a história, as motivações e as intenções do sujeito, bem como com o contexto de sua ação.
\end{abstract}

Palavras-chave: Significado. Compartilhamento. Sentido. Singularização.

\begin{abstract}
This paper proposes the concept of singularization as another means of approach to the understanding of how subjectivity is socially constituted in accordance with the approach of historical-cultural psychology. It begins with a historical overview of the introduction of sense and meaning in psychology, throughout modernity, marked by resistance to the consideration of culture in the constitution of psychological phenomena. Thereafter, we discuss the theoretical contributions brought by the concepts of internalization, appropriation and conversion. This discussion suggests the lack of a non-dualistic explanation for the transformation of collective knowledge into individual knowledge. We conclude that the concept of singularization emphasizes the active character of the subject and its interpretative action, to create singular versions for the meanings at the same time it reproduces them in social exchanges. It is clarified also that these versions are based on the creation of senses, which, in turn, are hinged to the history, motivations and intentions of the subject and the context of its action.
\end{abstract}

Keywords: Meaning. Share. Sense. Singularization.

Psicol. Argum. 2013 jul./set., 31 (74), 569-580 


\section{Introdução}

"Dessa forma, assim como cada ponto singular de um holograma contém a totalidade da informação do que representa, cada célula singular, cada indivíduo singular contém de maneira 'hologrâmica' o todo do qual faz parte e que ao mesmo tempo faz parte dele".

(Edgar Morin)

0 objetivo desta reflexão é demonstrar a adequação do conceito de singularização, como uma alternativa viável para a compreensão do processo de constituição social da subjetividade, quando se tem em vista o propósito de focalizar certos aspectos do fenômeno que não são contemplados ou evidenciados quando são utilizados os conceitos de internalização, conversão ou apropriação. 0 conceito de singularização prioriza aspectos distintivos da constituição da subjetividade, ao focalizar a atividade criativa do sujeito e a criação, por ele, de versões singulares para os significados socialmente constituídos com os quais se depara em suas relações sociais. Neste empreendimento, serão basilares os conceitos de significado e de sentido, firmemente estabelecidos na tradição teórica representada hoje pela psicologia histórico-cultural.

\section{Sentidos e significados na psicologia}

Namura (2004) identifica no idealismo platônico e no racionalismo aristotélico as raízes históricas das tendências filosóficas que sustentaram o debate entre razão e sensação. Esse debate teria orientado a psicologia para a adoção e construção da categoria sentido, em sua busca de explicação para "a necessidade do homem em dar um sentido à vida ou construir uma vida cheia de sentido" (Namura, 2004, p. 91).

Assim, duas abordagens se desenharam na compreensão inicial do sentido: uma que optou pelas sensações e percepções (foco nos órgãos dos sentidos) e outra que se voltou para a linguagem e a comunicação (foco nos sentidos denotativo e conotativo). Entretanto, o hegemônico sistema positivista se encarregou de rechaçar a segunda vertente, por sua incompatibilidade com a objetividade e a neutralidade científicas (Namura, 2004).

Apresentava-se, dessa forma, a dualidade empirismo e racionalismo. De um lado, a tradição lockeana, com a metáfora da mente como tábula rasa, transforma os órgãos dos sentidos em "porta de entrada dos processos cognitivos, dos processos de aprendizagem e da reflexão" (Namura, 2004, p. 93). Essa concepção de sentido deságua no associacionismo, behaviorismo etc., e sua influência pode ser compreendida com base em três pressupostos:

O que é externo e visível - o estímulo - é mais importante que o organismo, a admissão de que o anterior é mais relevante do que o que segue o desenvolvimento, e o que é pequeno e molecular, as ideias simples, é mais fundamental do que o que é grande e complexo, as ideias complexas (Namura, 2004, p. 94).

O empirismo de Locke na psicologia representa a perspectiva científica que se empenha em combater a perspectiva filosófica e firmar a psicologia como ciência. Essa perspectiva filosófica, representada principalmente pela tradição alemã, postula a origem inata das ideias e do conhecimento. A tradição filosófica alemã "contrapõe-se ao reducionismo molecular e ao dualismo cartesiano, postulando que a pessoa é a fonte dos atos e que a atividade é dotada de finalidade" (Namura, 2004, p. 94). Com as proposições inatistas de Leibnitz (relação entre o corpo, a alma, a auto-suficiência das mônadas e a sincronização divina) e os questionamentos de Berkeley (a rejeição ao sagrado e a experiência como único fenômeno passível de conhecimento) e Hume (a mente conhece somente seus próprios processos), passa a existir a compreensão de que "as ideias, percepções, motivações e a reflexão numa organização própria da mente geram e doam sentido ao mundo ao interagir com o meio ambiente" (Namura, 2004, p. 95), pois as sensações funcionam como fonte de conhecimento. A questão, portanto, é saber se esse conhecimento é ou não verdadeiro.

A autoria de um avanço teórico importante é atribuída a Hermann von Helmholtz. Ele vincula a origem do sentido "a um trabalho interior da mente, à influência da experiência passada e à personalidade do indivíduo" (Namura, 2004, p. 96). O problema é que, de um lado, ele recusa a possibilidade de um método baseado em observações e informações do sujeito, por suas implicações subjetivas, e, de outro lado, o método experimental não é capaz de apreender o sentido.

É nesse momento que entra em cena o "dualismo metodológico" de Wundt. Sua proposta é que os métodos psicofísicos sejam mantidos para estudar os processos elementares (sensações, percepções) e que os 
processos mentais sejam estudados pelo método histórico, buscando-se informações na cultura, por meio, por exemplo, da relação entre pensamento e linguagem. Em sintonia com Wundt, Franz Brentano afirma que o ato de significar um objeto é o que identifica o verdadeiro processo psicológico (Namura, 2004).

Segundo Farr (1999), na Alemanha, Dilthey considerou a história uma disciplina central da psicologia, sendo esta uma ciência humana e social e a mente humana concebida em termos históricos. De modo convergente, Wundt também concebia a mente como fenômeno histórico, complexo, que envolvia o pensamento e não apenas processos sensoriais básicos. Estudar o individual e o coletivo era, para Wundt, empreender dois projetos diferenciados. Durkheim situava essa possibilidade como algo marcante no âmbito das ciências humanas, ao considerar que distinguir representações individuais e representações coletivas significava distinguir a sociologia e a psicologia. Entretanto, para Wundt, ao invés de separação haveria entrelaçamento. Ou seja, o estudo dos processos mentais superiores seria uma forma de psicologia social.

Porém, as ideias de Wundt sobre questões subjetivas são criticadas, bem como sua proposta metodológica, e os sentidos são novamente afastados da ciência psicológica, o que reafirma sua preferência pelo método experimental e pelo elementarismo associacionista para compreender o psiquismo. De acordo com Namura (2004, p. 100), cabe à psicologia da Gestalt pôr os sentidos em evidência, ao propor que "as relações ou a combinação dos elementos sensoriais formam algo novo e significativo". Fortemente influenciada pela fenomenologia de Husserl, com sua ideia de "mundo vivido" como vivência do imediato e da conduta humana como algo intencional, a psicologia da Gestalt "coloca em pauta um princípio ativo estruturador da vida psíquica, trazendo a figura do indivíduo que conhece" (Namura, 2004, p. 101).

Segundo Namura (2004, p. 101), ainda que a psicologia da Gestalt supere o elementarismo das associações estímulo-resposta (S-R), "focaliza o aparelho sensorial, não a subjetividade que implicaria uma ideia de 'sentido', segundo uma configuração mais complexa, contemplando a ação, as finalidades, os sentimentos e interesses dos indivíduos". Desse modo, apesar de sair de uma compreensão molecular (sensações) para uma concepção molar (percepção complexa) dos fenômenos psicológicos, a Gestalt sucumbe ao formalismo experimentalista, "investe em experimentos com linhas, espaços e formas puras para demonstrar o caráter estrutural dos fenômenos da experiência e evita lidar com os objetos comuns da vida, repletos de significado" (Namura, 2004, p. 102); mantém a perspectiva da individualização na abordagem dos fenômenos psicológicos, que são vistos "como entidades naturais, abstratas, e as condições do ambiente social como dadas" (Namura, 2004, p. 102).

Farr (1999) aponta o conflito entre o positivismo e a fenomenologia como a expressão de um grave dilema da psicologia: ser uma ciência natural ou uma ciência humana e social, num contexto em que o método experimental, derivado das ciências físicas e biológicas (especialmente da fisiologia) poderia garantir sua cientificidade. 0 referido autor assinala que o método experimental, embora fosse o preferido, não era o único, pois havia o método comparativo, que fora utilizado por Darwin e que Wundt propunha em sua psicologia popular.

Namura (2004, p. 104) faz referência à psicanálise como uma das correntes teóricas que participam do processo de introdução do sentido na ciência psicológica: "um dos méritos de Freud foi ter transgredido a hegemonia da razão, e, nesse bojo, libertou o sentido da necessidade de responder pela veracidade do conhecimento". Na psicanálise, "o sentido é revelado quando se explica a função das manifestações psíquicas na conduta humana" (lapso de memória, atos falhos, sonhos etc.) (Namura, 2004, p. 104). A psicanálise compreende o sentido como algo que deriva do conteúdo psíquico latente, inconsciente, em função do que, mesmo sendo este "atravessado pela cultura, o arranjo que cada sujeito fará dos significados partilhados pela cultura é bastante pessoal" (Namura, 2004, p. 105). Essa singularidade assenta-se, porém, em conteúdos sexuais preexistentes.

Além dos autores até aqui citados, outras vozes se ergueram em oposição ao positivismo, ensejando o estudo do sentido, tais como: "Mead (1863-1931) e o 'behaviorismo social', Weber (1864-1920) e a 'imputação de sentido', e o historicismo de Dilthey (18331911), todos contemporâneos de Vygotsky" (Namura, 2004, p. 107). Esta autora aponta, ainda, a teoria das representações sociais como uma das contribuições mais recentes, na busca da compreensão de significados e sentidos, ao estudar os conhecimentos produzidos coletivamente no cotidiano; ainda que Moscovici, inspirando-se em Durkheim, não privilegie as singularidades, mas os compartilhamentos.

Orientando-nos por Touraine (1995), compreendemos que, nas visões da sociedade tradicional,

Psicol. Argum. 2013 jul./set., 31 (74), 569-580 
sujeito e objeto se confundiam. O homem estava sujeito a forças divinas e submetido a um destino de cuja elaboração não podia participar. Só lhe era possível conformar sua ação a uma ordem estabelecida. 0 avanço pela Modernidade significou uma crescente separação entre o sujeito e os objetos, um sujeito que buscava desvendar as leis que ordenavam os objetos no mundo. Emergia ali um sujeito que era, antes de tudo, liberdade e criação. Nesse sentido, Touraine (1995) conclui que, da mesma forma que a Modernidade não pode ser concebida sem a racionalização, também não o pode sem o sujeito.

Portanto, "não existe modernidade a não ser pela interação crescente entre o sujeito e a razão, entre a consciência e a ciência" (Touraine, 1995, p. 219). Se o homem é passível de um conhecimento objetivo, por seu pertencimento à natureza, que o constitui como objeto, também enseja outras possibilidades de conhecimento sobre si mesmo, por ser sujeito e subjetividade.

Entretanto, a psicologia não assumiu para si essa tarefa, na modernidade. Segundo Rey (2005), o modelo cartesiano-newtoniano de ciência e o positivismo, reinantes à época, mantiveram os psicólogos afastados do tema da subjetividade. Mesmo assim, a modernidade, ao enfatizar a objetividade, possibilitou, dialeticamente, a emergência da subjetividade e, subsequentemente, na pós-modernidade, a convivência de dois modelos contraditórios: a visão quantitativa e determinista e outra visão orientada "para uma realidade de caráter sistêmico, dialética e dialógica" (Rey, 2005, p. 73).

\section{Constituição social da subjetividade}

Segundo Bruner (1997), uma psicologia que assume os significados como seu objeto de estudo, torna-se necessariamente uma psicologia cultural. Para essa psicologia, importa "entender como os seres humanos interpretam seus mundos e como interpretamos os atos de interpretação deles" (Bruner, 1997, p. xi). Então, uma psicologia centrada exclusivamente no indivíduo torna-se inviável, em função da participação do ser humano na cultura e porque é através dela que o ser humano realiza "seus poderes mentais" (Bruner, 1997, p. 22).

Por conseguinte, uma psicologia cultural opta por focalizar as ações (e não os comportamentos), por serem estas fundadas em estados intencionais e situadas em um contexto cultural. Isto é, para entender o ser humano, é preciso entender "como suas experiências e seus atos são moldados por seus estados intencionais" (Bruner, 1997, p. 39). Porém, torna-se imprescindível não perder de vista que "a forma desses estados intencionais se realiza apenas através da participação em sistemas simbólicos da cultura" (Bruner, 1997, p. 39).

Em síntese, segundo Bruner (1997, p. 28), "a cultura e a busca por significado dentro da cultura são as causas adequadas da ação humana". Sendo assim, para interpretar cientificamente os significados e a produção de significados, é necessário "especificar a estrutura e a coerência dos contextos mais amplos nos quais significados específicos são criados e transmitidos" (Bruner, 1997, p. 60).

Nas origens desta tradição teórica encontramos a eminente figura de Vygotsky. Conforme Namura (2004), Vygotsky propôs a superação dos reducionismos objetivistas e subjetivistas, construindo uma nova síntese através de uma abordagem dialética, "a partir da oposição entre as forças e concepções naturalista e idealista” (Namura, 2004, p. 106).

Conforme Van der Veer e Valsiner (1996), Vygotsky e Luria, estimulados pelo trabalho de etnógrafos, abraçaram a ideia, que seria fundamental para a teoria histórico-cultural, de que pessoas de diferentes culturas e épocas apresentam os mesmos processos psicológicos inferiores, mas diferem quanto aos processos psicológicos superiores. De acordo com os autores, essa ideia já se apresentava no trabalho de Lévy-Bruhl. Sendo assim, não apenas o conteúdo do pensamento seria diferente entre pessoas de culturas diversas, mas até mesmo as maneiras de pensar seriam diferentes.

Segundo Van der Veer e Valsiner (1996), Vygotsky argumentava que tanto a forma quanto o conteúdo do pensamento humano têm os sistemas simbólicos disponíveis na cultura como seus fundamentos. Para que se produzisse uma integração entre o plano cultural e o plano individual, haveria um movimento de interiorização: "Vygotsky afirmava em geral que os sistemas de signos culturais são primeiramente dominados em um ato manifesto e só mais tarde podem começar a funcionar internamente, após um processo complexo de internalização" (Van der Veer \& Valsiner, 1996, p. 244).

Com isso, Vygotsky passou a dedicar atenção especial à linguagem, bem como à relação que esta mantém com o pensamento, buscando sua gênese numa perspectiva histórica: 
A história dos seres humanos era, para Vygotsky, a história de artefatos, de órgãos artificiais. Esses artefatos permitiram que os seres humanos dominassem a natureza, assim como o instrumento técnico da fala permitiu-lhes dominar seus próprios processos mentais (Van der Veer \& Valsiner, 1996, p. 225).

Vygotsky concebia a relação entre palavras e pensamentos como um processo, como um movimento do pensamento à palavra e desta ao pensamento. A constituição das funções psicológicas superiores ocorreria em dois momentos distintos, tendo a linguagem como suporte ou mediação:

A combinação por Vygotsky da ideia do domínio de instrumentos com a ideia da origem social das funções psicológicas superiores baseia-se na lei de Pierre Janet de que as funções psicológicas aparecem duas vezes na vida de um sujeito: primeiro, como uma função interpessoal, depois como uma função intrapessoal (Van der Veer \& Valsiner, 1996, p. 84).

No plano intrapessoal, pensamento e linguagem manifestam-se como fala interior, que seria uma fala para si mesmo e não para os outros. Segundo Van der Veer e Valsiner (1996, p. 397), Vygotsky encontrou em Paulhan a noção de sentido, que lhe permitiu avançar na compreensão do complexo fenômeno que focalizava e afirmar, por exemplo, que, na fala interior, "o sentido tem precedência sobre o significado". Sendo assim, depreende-se, logicamente, que, no plano interpessoal ou coletivo, ocorre o contrário: o significado tem precedência sobre o sentido.

A partir de Vygotsky, inicia-se o desenvolvimento de uma compreensão dialética de processos, como os cognitivos e afetivos, os sociais e individuais, que a Psicologia vinha mantendo apartados, até então. A organização psíquica do ser humano passa a ser vista como um sistema qualitativamente diferenciado que comporta a simultaneidade desses processos. Sendo assim, o social e o biológico não desaparecem, mas se integram (Rey, 2005).

Segundo Cole e Scribner (2000), a orientação básica do materialismo dialético é que os fenômenos sejam abordados como processo, ou seja, enquanto movimento e enquanto mudança. 0 desenvolvimento das mudanças, que são qualitativas e quantitativas, tem sua história. Tomando essa lógica como seu fundamento, Vygotsky explicou a transformação dos processos psicológicos primários em processos psicológicos complexos.

Ainda de acordo com Cole e Scribner (2000, p. 9), para o materialismo histórico, "mudanças históricas na sociedade e na vida material produzem mudanças na "natureza humana" (consciência e comportamento)". Vygotsky, então, apropriou-se das concepções de Engels acerca do trabalho humano e do uso de instrumentos. Para Engels, através do trabalho e do uso de instrumentos, "o homem transforma a natureza e, ao fazê-lo, transforma a si mesmo" (Cole \& Scribner, 2000, p. 9). Essa apropriação permitiu que Vygotsky concebesse a linguagem, ou os sistemas simbólicos, como o instrumento por excelência, que, sendo produzido culturalmente, promove transformações na dimensão individual, isto é, na subjetividade.

Contudo, ao advogar a constituição social do ser humano, Vygotsky fez surgir uma polêmica, que se mantém até hoje, em torno da formação do psíquico a partir do social. A questão básica consiste em compreender como a psique se desenvolve e se configura histórica e culturalmente, sem que essa compreensão seja aprisionada por um esquema dualista em que a dimensão social aparece como causa externa e a dimensão subjetiva como seu efeito interno.

Vygotsky (2000a, p. 74) buscou uma saída para o impasse por meio do conceito de interiorização (ou internalização), que seria a "reconstrução interna de uma operação externa". Mais claramente, "uma operação que inicialmente representa uma atividade externa", isto é, conduzida entre pessoas, é reconstruída pelo indivíduo, "tendo como base as operações com signos” (Vygotsky, 2000a, p. 75), e passa a ocorrer internamente. 0 que é reconstruído internamente são as formas culturais de comportamento. Esse processo de "internalização" envolve dois momentos: o primeiro é externo, social, interativo, dialógico, entre pessoas (interpsicológico) e o segundo é individual, interior (intrapsicológico).

A interiorização seria considerada mais tarde, entretanto, como afirma Rey (2005, p. 78), "uma forma de manter a dualidade em outros termos", pois, ainda assim, algo externo se movimenta para dentro. A solução que este autor propõe é baseada no conceito de subjetividade social. Ele sugere que a própria cultura funciona como um sistema subjetivo gerador de subjetividades. Nessa visão, os processos e instituições sociais podem ser compreendidos como comportando uma dimensão subjetiva.

Psicol. Argum. 2013 jul./set., 31 (74), 569-580 
O indivíduo é constituinte da cultura e é, também, por ela constituído.

Portanto, a subjetividade é apresentada por Rey (2005) como um sistema complexo, produzido nos níveis social e individual, simultaneamente. Desse modo, supera-se, segundo o autor, a perspectiva em que os processos sociais são considerados externos em relação aos indivíduos. Ele define a subjetividade social como complexo sistema de configuração subjetiva, constituído por elementos de sentido procedentes de diferentes espaços da vida social. Esses espaços estão estreitamente articulados entre si, de tal modo que o trânsito de sentidos, na ação ou expressão individual, transcende limites espaço-temporais. Ou seja, elementos de sentido gerados em outros espaços, em outros momentos da vida do indivíduo, migram e se articulam aos sentidos produzidos no espaço da vida social em que o indivíduo atua no momento presente.

Nosso entendimento é o de que a construção teórica de Rey (2005) tem o mérito de atualizar aspectos importantes da perspectiva inaugurada por Vygotsky. 0 autor amplia a visão da complexidade do fenômeno, notadamente no que se refere ao plano social. Entretanto, ainda que torne mais inteligível como se configura a indissociabilidade entre o plano social e o plano individual, não esgota o esclarecimento do problema de como se dá a gênese social do segundo, já que a subjetividade individual não se dissolve na subjetividade social. Na literatura, a explicação continua sendo baseada em soluções parciais, como veremos mais adiante. Apesar disso, o recorrente uso do termo internalização, na literatura psicológica, com o significado atribuído por Vygotsky, atesta sua utilidade e importância, inegavelmente, e, em consequência, a necessidade de mais estudos a respeito.

Podemos perceber que a categoria internalização propicia uma compreensão ainda inovadora na atualidade. Porém, a pergunta que sugere e o problema que ela implica são intrigantes e ainda estão a indicar possibilidades. A pergunta é simples: como se dá o processo de internalização? E o problema, em contrapartida, tem se mostrado assaz espinhoso: como explicar isso sem resvalar pelos clássicos dualismos (individual x social, interno x externo, objetivo x subjetivo etc.)?

Sendo assim, aderimos à ideia de que a noção de interiorização contraria a perspectiva dialética de Vygotsky e conserva a apontada dualidade em outros termos. Entretanto, consideramos que o que é mais problemático na teorização do autor é, essencialmente, a necessidade e o intuito de situar a constituição da subjetividade como fenômeno socialmente produzido e, ao mesmo tempo, manter bem marcada a distinção entre indivíduo e sociedade. Isso conduziu Vygotsky a ressaltar a temporalidade (sequência de momentos que caracterizam o antes e o depois) e a espacialidade (o externo e o interno) do movimento, ao invés da simultaneidade, da bilocalidade e da bidirecionalidade, por exemplo. Essa ênfase ofusca outra parte muito importante, indicada pelo próprio autor, ao utilizar termos e expressões como reconstrução radical, transformação, mudanças nas leis e incorporação a um novo sistema (Vygotsky, 2000a, pp. 74-76).

Vygotsky (2000a) apresenta a ideia de "reconstrução individual". Ele próprio sugere como isso ocorre, como o sujeito é ativo nesse processo, como interpreta os conteúdos e práticas sociais. Nesse sentido, a linguagem é fundamental, bem como sua relação com o pensamento. 0 problema na teorização de Vygotsky são as noções de externo e interno envolvendo a passagem do social ao individual.

Parece-nos extremamente oportuno o esclarecimento de Rey (2009), ao afirmar que, quando Vygotsky propõe o conceito de interiorização (ou internalização), está a adotar uma posição inicial no processo de construção de uma concepção do psiquismo como sendo constituído a partir do social. Apesar de focalizar as funções psíquicas como um sistema, ele ainda as representa apenas em termos cognitivos. Mais tarde, a partir de 1933, ao incluir em sua consideração os processos criativos e a história do sujeito que atua, Vygotsky começa a superar, através do conceito de sentido, os dualismos mantidos naquela posição inicial. Há que se considerar também possíveis problemas ocorridos nas traduções das obras do referido autor.

Podemos notar esse movimento de superação em um texto publicado originalmente em 1935. Nele, Vygotsky (1994) afirma que só podemos explicar o papel do ambiente no desenvolvimento da criança quando conhecemos a relação entre ela e seu ambiente. Mas devemos considerar que tanto o ambiente quanto a criança são sempre mutantes, estão sempre em movimento. Mesmo quando um ambiente específico muda pouco, a criança continua mudando e, por isso mesmo, o ambiente passa a ter um significado diferente para ela. Consequentemente, a relação entre ambos muda. 
Os fatores essenciais que explicam a influência do ambiente sobre o desenvolvimento psicológico de crianças, bem como sobre o desenvolvimento de suas personalidades conscientes, são constituídos por suas experiências emocionais. Isto é, não são os fatores socioculturais em si mesmos que determinam tal influência. Eles são refratados pelo prisma da experiência emocional da criança e pela forma como ela toma consciência da situação e a interpreta (Vygotsky, 1994).

Por conseguinte, a mesma situação e os mesmos eventos ambientais podem influenciar o desenvolvimento de várias pessoas diferentes de modos diferentes, dependendo da idade ou do estágio em que estas se encontrem. Cada pessoa apresenta uma atitude diferente quanto à situação ou a vivencia de modo diverso. Numa experiência emocional sempre lidamos com uma unidade indivisível de características pessoais e características situacionais. Não é essencial saber quais são as características constitucionais da criança, mas o papel que elas desempenham na relação da criança com a situação. Qualquer evento ou situação no ambiente da criança terá um efeito diferente sobre ela, dependendo de como e com que extensão compreenda seu sentido ou significado (Vygotsky, 1994).

Para Vygotsky (1994), o desenvolvimento do pensamento da criança em si mesmo, o significado de suas palavras, é o que determina o novo relacionamento que pode existir entre o ambiente e os diferentes processos desenvolvimentais. 0 ambiente determina o tipo de desenvolvimento dependendo do grau de consciência que a criança tenha logrado alcançar sobre este ambiente.

A consideração básica de Vygotsky (1994) é que o ser humano é de natureza social. Por isso, seu desenvolvimento consiste, dentre outras coisas, em dominar certas formas de atividade e de conhecimento que têm sido aperfeiçoadas pela humanidade durante o processo de desenvolvimento histórico. O ambiente é, ao mesmo tempo, situação e tradição. Aquilo que aparece na situação tem sua história, por ser socialmente construído; ou seja, é historicamente processado e socialmente situado.

Portanto, durante o curso do seu desenvolvimento, as crianças adquirem como sua propriedade pessoal aquilo que originalmente representou somente uma forma de sua interação externa com o ambiente. As funções psíquicas superiores da criança, os atributos que são especificamente humanas, inicialmente se manifestam como formas do comportamento coletivo da criança, como uma forma de cooperação com outras pessoas, e só mais tarde elas se tornam funções individuais internas da própria criança (Vygotsky, 1994). Para o autor, a emergência da fala interior seria um exemplo desse processo. Originalmente a fala representa um meio de comunicação entre pessoas. Isto é, manifesta-se como função social. Mas, gradualmente, a criança aprende como usar a fala para si mesma, seus processos internos. Além de meio de comunicação, a fala torna-se íntima, silenciosa, meio dos processos de pensamento da criança.

Nesse momento, Vygotsky (1994) recorre à noção de apropriação para dizer como características especificamente humanas aparecem primeiro no plano social para depois constituírem a subjetividade individual, ou seja, como algo próprio da criança. Nesse ponto, ao estruturar uma temporalidade extensiva, o autor indica a separação entre o interno e o externo, mantendo a dicotomia embutida em sua concepção de internalização.

Smolka (2000, p. 36), ao comentar sobre os problemas implicados no conceito de internalização, prefere realçar o valor do construto como indicador de um "posicionamento epistemológico e ideológico"; e sugere a possibilidade de adotá-lo como um "princípio relacional". Essas parecem ser alternativas bastante coerentes com a reflexão que desenvolvemos aqui.

O intuito desta reflexão é discutir sobre algumas das alternativas teóricas que tem sido propostas, a partir de Vygotsky, para elucidar o fenômeno indicado pelo conceito de internalização, qual seja, a constituição social da subjetividade. Focalizaremos especialmente os conceitos de internalização, conversão e apropriação. Ao utilizar um ou outro dos conceitos citados anteriormente, os autores optam por dar visibilidade a um ou outro aspecto do fenômeno, abdicando da tentativa de configurar a sua totalidade. Smolka (2000) aponta alguns termos que têm sido usados para significar algum aspecto do fenômeno indicado por Vygotsky como sendo a internalização das experiências sociais que se transformam nas funções psicológicas superiores: interiorização, incorporação, apreensão, assimilação, apropriação e conversão. A autora considera que esses termos designam o modo pelo qual "um indivíduo adquire, desenvolve e participa das experiências culturais" (Smolka, 2000, p. 27).

Psicol. Argum. 2013 jul./set., 31 (74), 569-580 
Diante da complexidade do fenômeno por ele apontado, e apesar de sua clara preferência pelo conceito de internalização, o próprio Vygotsky precisou recorrer a outros conceitos para avançar na compreensão do processo de constituição social do ser humano. Optando pelo verbo ou pelo substantivo, Vygotsky usou, em um ou outro momento, as noções de apropriação, incorporação e conversão, por exemplo. Preferimos, contudo, priorizar, nesta discussão, os conceitos de apropriação, conversão e internalização (ou interiorização), por considerarmos que são os mais utilizados entre os teóricos mais recentes do campo da psicologia social. Do nosso ponto de vista, todos esses conceitos aportam contribuições importantes para a compreensão do fenômeno, mas, cada um deles, em separado, é insuficiente para a compreensão de sua totalidade.

Rogoff (1998) identifica três usos do termo apropriação. No primeiro, é equivalente a internalização. Mas é importante assinalar que a autora considera a internalização como processo "em que algo estático é levado além de um limite do externo para o interno..." (Rogoff, 1998, p. 132). No segundo uso, há ainda equivalência, segundo a autora, entre apropriação e internalização, mas esse algo externo que é trazido para o interno passa por transformações, não é estático, precisa "se adequar ao propósito do novo "possuidor" (Rogoff, 1998, p. 134). 0 uso que a própria autora faz seria o terceiro. Nesse caso, apropriação significa participação em atividade, em que as pessoas promovem transformações mútuas, no campo dos significados. E, ao fazê-lo, tornam-se preparadas para participar de atividades similares posteriormente.

Para Smolka (2000), o termo apropriação pode ter também três sentidos diferentes. Pode supor "algo que o indivíduo toma" de algum lugar e de alguém e atribui-lhe "propriedade particular" (Smolka, 2000, p. 28). Pode também referir-se à possibilidade de "tornar adequado, pertinente, aos valores e normas socialmente estabelecidos" (Smolka, 2000, p. 28). Por último, o tornar próprio pode significar uma transformação mútua de sujeitos e objetos, por meio do uso de instrumentos.

Pino (2005) considera que o termo conversão é mais indicado para significar o fenômeno a que Vygotsky se refere ao tratar sobre o processo de internalização. Este autor identifica três acepções para o termo conversão: 1) a ideia de réplica; 2) de mudança do sentido atribuído às coisas; 3 ) ressignificação, como na conversão religiosa. 0 autor considera a última acepção mais adequada para expressar a ideia de que algo que ocorre no mundo público passa a ocorrer também no mundo privado. Para ele, "isso implica duas coisas: uma transposição de planos e uma mudança de sentido nas relações sociais" (Pino, 2005, p. 112).

0 entendimento de Pino (2005) é o de que na conversão das relações interpessoais em relações intrapessoais a significação dessas relações permanece, mas muda de estado social para pessoal (mudança de estado) e de agente externo para agente interno (mudança de direção).

\section{0 processo de singularização}

Partindo do conceito de internalização, o trânsito pelos conceitos de apropriação e conversão nos convence de que essa itinerância permite uma visualização crescentemente complexa do fenômeno indicado por Vygotsky para dar conta de um entendimento plausível acerca do processo que resulta na constituição social da subjetividade.

Ao mesmo tempo, ficamos também convencidos de que esses conceitos deixam a descoberto aspectos outros de suma importância para o conhecimento do fenômeno em pauta. Ou, ao menos, não lhes dedicam a devida ênfase. Compreendemos, então, que os conceitos a que nos referimos proporcionam, em suas similaridades e diferenças, uma visão ainda parcial do fenômeno. Por essa razão, avaliamos a pertinência de usar o conceito de singularização para, desse modo, contribuir com esse esforço aproximativo à compreensão da totalidade do fenômeno. Ao fazê-lo, levamos em consideração as indicações advindas dos conceitos de internalização, de apropriação e de conversão. Mas não nos limitamos a elas. Ao invés disso, pretendemos apontar determinados aspectos que, à luz daqueles conceitos, perdem visibilidade.

Nesse sentido, parece-nos bastante pertinente a seguinte afirmação de Rey (2005, p. 118):

Uma das exigências para a construção teórica da subjetividade é a produção de categorias que nos permitam dar conhecimento sobre o caráter geral de seu funcionamento e formas de organização, e que, por sua vez, nos permitam especificar as formas que essa organização adota no nível singular... 
O conceito de singularização permite o entendimento de que o processo de subjetivação comporta, basicamente, a criação do que é singular ao longo do processo de produção e reprodução do que é comum, do que é coletivo. Concomitantemente, o referido conceito possibilita dizer como isso acontece, conforme nosso ponto de vista, tendo em consideração as contribuições de Vygotsky e de outros autores. 0 conceito de singularização prioriza aspectos distintivos da constituição da singularidade, ao focalizar a atividade criativa do sujeito e a criação, por ele, de versões singulares para os significados socialmente constituídos, com os quais se depara em suas relações e nas práticas sociais das quais participa.

Portanto, consideramos, por meio do conceito de internalização, essa passagem que se dá de um plano para outro, do interpessoal ao intrapessoal ou do social ao individual/psicológico. Essa passagem implica, segundo Vygotsky (2000a), reconstrução interna da atividade externa, reconstrução que nos autoriza a pensar em transformação dos conteúdos, dos significados socialmente construídos. 0 conceito de conversão se encarrega de clarificar a natureza dessa transformação, situando-a como ressignificação. Na ressignificação, o sentido atribuído às coisas é modificado. Muito próxima dessa compreensão está a ideia de apropriação em Smolka (2000). Tanto no sentido de "algo que o indivíduo toma" de algum lugar e de alguém, atribuindo-lhe "propriedade particular", imprimindo-lhe a marca da singularidade, quanto no sentido de transformação mútua de sujeito e objeto nesse movimento de tornar próprio. Ainda assim, do nosso ponto de vista, uma lacuna permanece e dela emerge a seguinte pergunta: como esse sentido é modificado?

Percebemos que, em vários momentos, Vygotsky (2000a) se refere ao fenômeno da internalização expressando uma compreensão que desdiz essa noção de mera passagem de conteúdos sociais à interioridade individual. 0 que fazemos, então, é reafirmar sua concepção, enfatizando o caráter ativo do indivíduo para a emergência da experiência subjetiva, fenômeno de uma ordem qualitativamente distinta do social. Ao fazê-lo, sugerimos que as produções simbólicas, socialmente desenvolvidas, não "adentram" o indivíduo e, sim, que o indivíduo, a partir dessas produções, que lhes são apresentadas e das quais participa nas interações e intercâmbios sociais, constrói suas próprias interpretações ou versões.
Salientamos, portanto, a experiência e o desenvolvimento de habilidades do sujeito interpretante.

Dito de outro modo, nosso entendimento é o de que ocorre uma convergência entre a ação do indivíduo, que é intencionalmente fundada e orientada para a busca de significados, como diria Bruner (1997, p. 40), e os "padrões inerentes aos sistemas simbólicos da cultura". Nessa convergência, mediada pela linguagem e pelas ações também intencionais de outros interagentes, o sujeito atua de modo inventivo, produzindo configurações simbólicas singulares em sua expressão, socioculturalmente situada, e, simultaneamente, na constituição de sua subjetividade.

Poderíamos, no máximo, dizer que os significados, socialmente construídos, são interpretados pelo sujeito. Somente assim poderão ser por ele utilizados. Um sujeito que busca significados, transitando em um universo constituído por sistemas simbólicos, é, necessariamente, um sujeito interpretante. A atividade interpretativa que o sujeito realiza em torno dos significados, integrando-os à sua história, à sua afetividade, resulta na produção de sentidos. Os sentidos equacionam os significados circulantes em relação à história pessoal do sujeito, atualizando-a quanto às circunstâncias, em termos cognitivos e afetivos. Os sentidos funcionam como versões pessoais, vivenciadas, das versões socialmente construídas e apresentadas pelo outro na interação. 0 sujeito/agente social imprime os significados, resultantes de acordo intersubjetivo, e os sentidos de sua experiência/história pessoal em suas ações e práticas sociais das quais participa.

O sujeito pensa e sente e pode reconhecer essas experiências como suas, porque essas experiências permitem que ele se reconheça. 0 sujeito se apropria de significados (socialmente construídos), à medida que constrói, para eles, versões ancoradas em sua história e em sua experiência presente. Essas versões são plenas de sentidos e, portanto, impregnadas de afetividade. A atualidade da ação do sujeito se entrelaça ao espaço social em que está inserido e, simultaneamente, sua história o conecta a outros espaços sociais pelos quais já transitou, construindo sentidos, como sugere Rey (2005). Ao mesmo tempo, a ação do sujeito expressa e é orientada por esses significados e sentidos.

Assim, os indivíduos humanos se apropriam dos significados do seu grupo cultural e os expressam ao estabelecer comunicação com os outros. A relação

Psicol. Argum. 2013 jul./set., 31 (74), 569-580 
do indivíduo com a sociedade, com a cultura, com o mundo, não é direta, mas mediada pelas interações sociais e pela linguagem. A linguagem tem origem social, viabiliza a simplificação e generalização da experiência e o ordenamento dos fenômenos e objetos em categorias conceituais. Seus significados vale ressaltar - são compartilhados pelos indivíduos da mesma cultura (Oliveira, 1992a).

O compartilhamento da linguagem inclui a negociação e reinterpretação de significados (Oliveira, 1992b). O pensamento e a fala estão envolvidos no significado da palavra, constituindo o pensamento verbal (Vygotsky, 2000b). Oliveira (1992b) distingue as duas dimensões do significado da palavra apontadas por Vygotsky. Uma dimensão é compartilhada pelos usuários (o significado propriamente dito) e funciona como um "núcleo estável de compreensão da palavra". A outra dimensão é o significado individual (sentido), “composto por relações que dizem respeito ao contexto de uso da palavra e às vivências afetivas do indivíduo" (Oliveira, 1992b, p. 81). 0 sentido, portanto, é mais concreto do que o significado propriamente dito e, também, mais abrangente, pois que o inclui.

O sentido é a expressão da indissociabilidade entre o plano social e o plano individual. Ao expressar a singularidade do sujeito, o sentido traz em seu bojo o significado, a dimensão do compartilhamento, do conhecimento coletivo. Sobre estas questões, Rey (2005, p. 235) assim se expressa: "Para o sujeito, o sentido aparece como registro emocional comprometido com os significados e as necessidades que vão desenvolvendo-se no decorrer de sua história". Devemos acrescentar que o sentido inclui em sua configuração motivações diversas e intencionalidades. Mas o próprio Vygotsky (2000b, p. 181) vai além, ao assegurar que "o sentido de uma palavra é a soma de todos os eventos psicológicos que a palavra desperta em nossa consciência”. Sobre este ponto específico, devemos retornar a Rey (2009, p. 50), pois este autor, de modo acertado, afirma que, apesar de definir o sentido com relação à palavra, Vygotsky o configura cada vez mais como sistema, "e a palavra vai cedendo lugar a uma nova formação que tem seu status próprio na vida psíquica”.

Além disso, Rey (2009, p. 51) assinala que "a categoria de sentido, como aparece na obra de Vygotsky, representa uma unidade constitutiva da subjetividade, capaz de expressar processos complexos de subjetivação naquilo que têm de dinâmico, irregular e contraditório". Mas, não podemos esquecer que o próprio Vygotsky (2000b) já concebia o significado como "unidade do pensamento verbal" (p. 150) ou "como uma unidade tanto do pensamento generalizante quanto do intercâmbio social” (p. 8), situando par a par o pensamento e a linguagem.

Como lidar, então, com a indicação dessas duas unidades? Com base em nosso julgamento, a questão é simples, a despeito da complexidade do fenômeno. Antes de tudo, consideramos que essas indicações são coerentes e não constituem mútua exclusão. 0 que está em jogo é a possibilidade de apreender o fenômeno de modos diferenciados, dependendo do momento. Se o momento for constituído pela centralidade do intercâmbio social, será apreendida a prevalência do significado. Nesse caso, o sentido não deixa de existir. Torna-se subtexto, move-se nas entrelinhas ou insinua-se como motivação ou intencionalidade implícita. Se, entretanto, o momento for constituído pela centralidade do sujeito, o sentido assumirá a prevalência e a situação mostrar-se-á invertida. Vygotsky (2000b) já havia apresentado uma pista disso, ao caracterizar a fala interior (ou seja, a centralidade do sujeito). Para ele, um aspecto fundamental da fala interior era justamente a prevalência do sentido da palavra em relação a seu significado.

Na ilustração do processo de internalização, apresentada por Vygotsky (2000a), o impotente movimento da criança de pegar o objeto com as mãos é significado pelo adulto como gesto de apontar. Orientado originalmente ao objeto, torna-se, a partir daí, "um gesto para os outros", ou seja, “o movimento de pegar transforma-se no ato de apontar" (Vygotsky, 2000a, p. 74). Dito de outro modo, antes de tornar-se um significado para si (sentido), o gesto de apontar é um significado para os outros e entre os outros.

A tese de Vygotsky (2000a) de que as funções psicológicas superiores são relações sociais ou formas culturais de comportamento internalizadas nos conduz a pensar em termos de significado e de sentido. Pensamos, então, que, ao compartilhar um conhecimento coletivo, um significado, o sujeito produz sentido. Ao fazê-lo, transforma o conhecimento entre os outros, simultaneamente, em conhecimento entre nós e para si. A transformação do significado em conhecimento para si demanda uma produção de sentidos. Como a produção de sentidos não elimina o significado, mas o inclui numa configuração 
mais ampla e mais complexa, podemos dizer que o sujeito, ao imprimir suas singularidades ao significado, promove sua própria inclusão sociocultural e histórica. Isto é, converter um conhecimento para os outros em conhecimento para si exige a simultaneidade da conversão do conhecimento entre os outros em conhecimento entre nós.

A produção de sentido promove, simultaneamente, a singularização do conhecimento social e a socialização do pensamento. É pela atividade, pela ação, que o sujeito socializa seu pensamento e se inclui numa determinada comunidade do saber.

\section{Considerações finais}

Em síntese, priorizamos a atividade criativa do indivíduo, atividade que é essencialmente interpretativa sem se reduzir ao funcionamento cognitivo. Ao fazer isso, focalizamos aquilo que lança luz sobre a operação em que os significados socialmente constituídos são transformados pelo indivíduo. Percebemos, então, que o cerne dessa transformação é a construção de versões singulares, versões que só se tornam possíveis no movimento de integração entre os conhecimentos sociais e as vivências emocionais do indivíduo. Essas versões singulares são configurações de sentidos. Sua produção e o movimento de singularização constituem processos indissociáveis. Do mesmo modo, identificamos a indissociabilidade entre a singularização e os processos de compartilhamento (ou pluralização).

Consideramos, tal como Rey (2005) o faz, que a noção de prática social e o significado de participação que traz em si são fundamentais para a concepção de sujeito e para o reconhecimento da dimensão social como aspecto constitutivo da subjetividade individual. É importante, neste ponto, lembrar a afirmação de Touraine (1995, p. 220) de que "o sujeito é a vontade de um indivíduo de agir e de ser reconhecido como ator". Essa atuação é baseada em comportamentos que são a expressão de sua história pessoal e modifica o cenário material e social em que o ator se move. Não podemos, no entanto, deixar de notar que, nesta posição, as noções de participação e de prática social passam a constituir um elo consistente entre as categorias de sujeito e de cidadania, ainda que comportem contradições.

Guattari e Rolnik (1999, p. 33) afirmam que "a subjetividade está em circulação nos conjuntos sociais de diferentes tamanhos: ela é essencialmente social, e assumida e vivida por indivíduos em suas existências particulares". Reencontramos aqui a ideia que Rey (2005) cunhou como sendo a subjetividade social. A subjetividade está em circulação, bem como os indivíduos, em suas condições peculiares de existência. Logo, as formas pelas quais cada indivíduo vive e assume essa subjetividade ganham configurações singulares.

Para Guattari e Rolnik (1999, p. 33), essa vivência subjetiva situa-se entre dois pólos:

Uma relação de alienação e opressão, na qual o indivíduo se submete à subjetividade tal como a recebe, ou uma relação de expressão e de criação, na qual o indivíduo se reapropria dos componentes da subjetividade, produzindo um processo que eu chamaria de singularização.

No primeiro caso, o indivíduo põe-se numa posição passiva de mera reprodução da subjetividade social. No segundo caso, o indivíduo é ativo, criativo, e subverte aquilo que assume da subjetividade social, constituindo sua singularidade. Do nosso ponto de vista, essas duas possibilidades são vivenciadas pelo indivíduo concomitantemente, compondo amálgamas com diferentes nuances configurativas. Ou seja, ao mesmo tempo em que o indivíduo reproduz os significados, a mesmice, aquilo que é coletivamente compartilhado, subverte-o, atribuindo-lhe sentidos singulares, em consonância com sua história, emoções, motivos e intenções que se ligam à especificidade da situação.

\section{Referências}

Bruner, J. (1997). Atos de significação. Porto Alegre: Artmed.

Cole, M., \& Scribner, S. (2000). Introdução. In L. S. Vygotsky. A formação social da mente: $O$ desenvolvimento dos processos psicológicas superiores. (6. ed, pp. 1-19). São Paulo: Martins Fontes.

Farr, R. M. (1999). As raízes da psicologia social moderna. (2. ed.). Petrópolis: Vozes.

Guattari, F., \& Rolnik, S. (1999). Micropolítica: Cartografias do desejo. (5. ed.). Petrópolis: Vozes.

Psicol. Argum. 2013 jul./set., 31 (74), 569-580 
Namura, M. R. (2004). Por que Vygotski se centra no sentido: Uma breve incursão pela história do sentido na psicologia. Psicologia da Educação, 19(2), 91-117.

Oliveira, M. K. (1992a). Vygotsky e o processo de formação de conceitos. In Y. La Taille, M. K. Oliveira \& H. Dantas. Piaget, Vygotsky, Wallon: Teorias psicogenéticas em discussão (pp. 23-34). São Paulo: Summus.

Oliveira, M. K. (1992b). O problema da afetividade em Vygotsky. In Y. La Taille, M. K. Oliveira \& H. Dantas. Piaget, Vygotsky, Wallon: Teorias psicogenéticas em discussão (pp. 75-84). São Paulo: Summus.

Pino, A. (2005). As marcas do humano: Às origens da constituição cultural da criança na perspectiva de Lev S. Vigotski. São Paulo: Cortez.

Rey, F. L. G. (2005). Sujeito e subjetividade: Uma aproximação histórico-cultural. São Paulo: Pioneira Thomson Learning.

Rey, F. L. G. (2009). O social na psicologia e a psicologia social: A emergência do sujeito. (2. ed.). Petrópolis: Vozes.
Rogoff, B. (1998). Observando a atividade sociocultural em três planos: Apropriação participatória, participação guiada e aprendizado. In J. V. Wertsch, P. Del Rio \& A. Alvarez (Org.). Estudos socioculturais da mente (pp. 123-142). Porto Alegre: Artmed.

Smolka, A. L. B. (2000). o (im)próprio e o (im)pertinente na apropriação das práticas sociais. Cadernos Cedes, 20(50), 26-40.

Touraine, A. (1995). Crítica da modernidade. Petrópolis: Vozes.

Van der Veer, R., \& Valsiner, J. (1996). Vygotsky: Uma síntese. (3. ed.). São Paulo: Loyola.

Vygotsky, L. S. (1994). The problem of the environment. In R. Van der Veer \& J. Valsiner (Ed.), The Vygotsky reader (pp. 338-354). Oxford: Blackwell.

Vygotsky, L. S. (2000a). A formação social da mente: $O$ desenvolvimento dos processos psicológicos superiores. (6. ed.). São Paulo: Martins Fontes.

Vygotsky, L. S. (2000b). Pensamento e linguagem. (2. ed.). São Paulo: Martins Fontes. 